\title{
INCLUSÃO ESCOLAR E EDUCAÇÃO FÍSICA: A PARTICIPAÇÃO DOS PROFESSORES DE HORTOLÂNDIA- SP
}

\author{
Josiane Filus Freitas \\ Faculdade Adventista de Hortolândia, Hortolândia, São Paulo, Brasil \\ Paulo Ferreira Araújo \\ Universidade Estadual de Campinas, Campinas, São Paulo, Brasil
}

\begin{abstract}
Resumo
O objetivo deste artigo foi apresentar a participação dos professores de Educação Física na inclusão escolar de crianças com deficiência do município de Hortolândia-SP. Por meio da análise de conteúdo realizada a partir dos questionários aplicados, pudemos perceber que o grupo formado por 13 professores não participa no processo de identificação e encaminhamento de crianças para avaliação, não recebe informações sobre o aluno com deficiência, e realiza adaptações das atividades de aula. Concluímos que o município de Hortolândia necessita promover uma aproximação dos professores de Educação Física com o processo de inclusão escolar, por meio de cursos de sensibilização e formação continuada.
\end{abstract}

Palavras-chave: Crianças Com Deficiência. Educação Física. Organização Municipal.

\section{Introdução}

Buscando cumprir o proposto nas leis e decretos, as escolas brasileiras iniciam as tentativas por uma Educação Inclusiva. Com o término dos prazos propostos pelo Plano Nacional de Educação (BRASIL, 2001), observamos a chegada de muitas crianças com deficiência nas escolas e, a partir daí, uma série de dúvidas, medos, incertezas e mudanças tem rondado todos os agentes do processo educacional. Neste cenário encontramos o professor de Educação Física (EF).

Para Rodrigues (2003), há uma dimensão de aparências e uma dimensão de constatações a respeito da EF e suas relações com a inclusão escolar. Aparentemente, esta seria uma área curricular mais facilmente inclusiva devido à flexibilidade inerente aos seus conteúdos, o que conduziria a possibilidades para todos os alunos, utilizando-se da diferenciação curricular. Os professores de EF são vistos como profissionais que desenvolvem atitudes mais positivas perante os alunos, pois são mais flexíveis e dinâmicos diante dos problemas em aula. Além disso, entende-se que a aula de EF permite um amplo envolvimento de todos, pois sua or- 
ganização pode suscitar uma participação e um grau de satisfação elevados de alunos com níveis de desempenho muito diferentes.

No entanto, as constatações revelam que a atuação da EF não tem contribuído para a efetivação do processo de inclusão, uma vez que estudos nesta área apontam que as atitudes mais e menos positivas dos professores dependem de diversos fatores (gênero do professor, experiência anterior, conhecimento da deficiência, nível de ensino do aluno). Soma-se a isso a ausência de conteúdos sobre o assunto na formação profissional, assim como a falta de espaços e programas na escola para uma formação continuada (RODRIGUES, 2003).

Sobre essa questão, Salerno et al. (2012) revelam que muitos cursos de EF destinam apenas uma disciplina isolada para tratar desses assuntos e, muitas vezes, esta fica restrita apenas aos conhecimentos teóricos sobre as deficiências e suas classificações, conteúdos que não satisfazem as recentes preocupações relacionadas à inclusão social e educacional das pessoas com deficiência. Como resultado disso, os conceitos e pré-conceitos relacionados a essa população continuam a limitar a prática do professor de $\mathrm{EF}$, que, em muitos casos, não teve, durante a graduação, conteúdos que lhe possibilitassem pensar na diversidade e nas diferenças.

Após verificar as percepções de alunos de graduação em EF a respeito da Inclusão Escolar e da Educação Física, os autores concluíram que a disciplina Educação Física Escolar Especial tem uma grande contribuição para a formação desses futuros educadores, pois, a partir dela, discute-se a temática da inclusão, seus conflitos, medos, anseios e conquistas, favorecendo a formulação de novas ideias e reflexões sobre as possibilidades e as limitações desse processo. É importante destacar que, defendendo a Inclusão como "o real acesso às oportunidades" (ARAÚJO, 2003), deve-se buscar auxiliar os alunos da graduação a desenvolver a sensibilidade e o olhar para a diversidade que encontrarão na escola, considerando os educandos em suas individualidades e, principalmente, favorecendo as oportunidades necessárias ao desenvolvimento de todos.

Essa nova preocupação com a formação em EF permitirá, também, superar os reflexos do passado que ainda permeiam a prática profissional: a cultura desportiva e competitiva, que impede que muitos sejam participantes nas aulas (BRACHT, 2005; VAGO, 1996). Os padrões pré-estabelecidos e o favorecimento dos mais aptos, historicamente, fez com que muitas crianças e jovens, com deficiência ou não, fossem excluídos das aulas de EF. Seabra Junior (2006) verificou o esporte como atividade principal das aulas, assim como uma metodologia diretiva, comando/tarefa, o que sugere uma prática excludente e controladora, onde apenas os mais habilidosos podem participar.

Considerando todos os conteúdos da EF: jogo, esporte, dança, ginástica, luta e circo, destacamos que quando são ministradas atividades mais lúdicas, menos diretivas, e que não exigem um padrão pré-estabelecido, como no esporte, percebe-se uma interação natural entre os alunos. Estes, com ou sem deficiência, 
interagem sem discriminação durante as atividades, em alguns momentos até criando novas possibilidades para a participação de todos (FILUS, LIMA, RODRIGUES, 2005).

Isso não significa, no entanto, que o conteúdo esporte não deve ser trabalhado em aulas que se pretendem inclusivas. O que o professor precisa entender é que uma metodologia mais aberta a possibilidades favorece a criação e recriação de movimentos e permite ao aluno a exploração e o conhecimento do próprio corpo, descobrindo suas potencialidades e também suas limitações (SALERNO, 2009).

Florence (2002), em entrevistas com professores de EF, constatou que a insegurança que alguns deles sentem por se considerarem inaptos a trabalhar com alunos com deficiência em sua classe cai por terra ao vivenciarem a experiência. Segundo os entrevistados, eles buscaram meios ou simplesmente desenvolveram seu trabalho de forma comum e, à medida que foram ensinando, o medo foi desaparecendo. Com o passar do tempo, os professores se certificaram que os problemas não são tantos como pensavam e que as suas práticas e experiências dão conta das situações de aprendizagem, mesmo porque, as adaptações são sinalizadas pelo próprio aluno e os professores vão se conscientizando de que os alunos seguem caminhos diferentes na realização das atividades, e que isto é normal.

Soler (2005) apresenta a Pedagogia Cooperativa, baseada em Brotto (1999), como uma alternativa para aulas mais inclusivas. Para o autor, criando novos jogos nos quais todos possam vencer, independentemente de suas habilidades, estaremos possibilitando que aqueles com pouca habilidade motora possam participar e capacitar-se em suas dificuldades. Na cooperação o sentimento de empatia é intensificado, ou seja, as crianças se colocam no lugar do outro e podem, assim, perceber suas limitações e possibilidades, ajudando-se mutuamente.

Essa prática de possibilitar a participação de todos é afirmada por Silva, Seabra Junior e Araújo (2008), que apontam ações a serem tomadas pelos professores que são determinantes e influenciadoras para que isso ocorra: favorecer a aprendizagem dando oportunidades e adaptando atividades; orientar a aprendizagem; instruir e dar feedback durante e após a atividade; estimular a participação; incentivar e envolver os alunos, sendo acessível ao diálogo.

Salerno (2009) destaca também a interação entre alunos com e sem deficiência nas aulas de EF e em sala de aula. Após um levantamento de pesquisas, a autora percebeu que a interação entre esses dois grupos pode ocorrer ou não, e sugere que ela está intimamente ligada ao estímulo ou desestímulo gerado pelas atitudes dos envolvidos. Neste sentido, destacamos o papel do professor de EF.

Mesmo considerando uma maior facilidade para promover a inclusão nas aulas de EF, Seabra Junior (2006, p. 95) destaca um ponto importante:

[...] cada professor, no interior de sua individualidade e no seu processo de formação, apresenta-se como ser único, com con-

Pensar a Prática, Goiânia, v. 17, n. 1, p. 01-294, jan./mar. 2014 
vicções e perspectivas de mundo construídas sobre diferentes pilares, conforme o momento histórico e político vivenciado. Assim, passa a ser necessário considerar que a atuação do professor deve ser entendida como uma inter-relação de diferentes aspectos, além dos conhecimentos acadêmicos. Essas diferenças e particularidades podem refletir diretamente na forma de ação do professor.

Sendo assim, a busca por diferentes estratégias e possibilidades para todos os alunos perpassa pelos conceitos e pré-conceitos vividos e compreendidos por cada sujeito no decorrer de sua vida. A superação de visões negativas a respeito da pessoa com deficiência e suas potencialidades nas aulas de EF e nas demais disciplinas escolares devem ser trabalhadas nos cursos de formação, com sensibilização e disseminação de conhecimentos sobre as deficiências, já que para uma prática inclusiva "esse processo de mudanças deve ocorrer de dentro para fora, de forma permanente, na busca de entender-se a si mesmo e de reconhecer o outro na sua identidade própria..." (SEABRA JUNIOR, 2006, p. 96).

Essa questão novamente nos remete às atitudes e pensamentos a respeito da pessoa com deficiência, e que são ponto de partida para que a Educação Inclusiva aconteça. No entanto, mesmo que muitos ainda vejam essa população como carente de possibilidades físicas, intelectuais, entre outras, sua presença nas escolas é garantida por lei e a cada ano mais crianças com deficiência têm se matriculado e frequentado as escolas.

Com vistas a entender esse processo e todos os entraves que o envolvem, focamos nosso olhar em um município específico e sua organização para a inclusão das crianças com deficiência nas escolas regulares. O objetivo deste artigo foi apresentar a participação dos professores de Educação Física na organização da inclusão escolar de crianças com deficiência do município de Hortolândia-SP.

\section{Métodos}

Para nossa pesquisa, buscamos desenvolver uma investigação qualitativa, que, segundo Demo (2009), trabalha com o lado subjetivo dos fenômenos, buscando depoimentos que se transformam em dados relevantes, oriundos de pessoas simples.

O município pesquisado foi Hortolândia-SP. Hortolândia tem registros de crianças com deficiência incluídas na Rede Municipal de Ensino desde 1993. No entanto, um serviço de atendimento específico a essas crianças só foi organizado a partir de 2009, por meio da adesão ao Serviço Itinerante, um projeto piloto realizado em seis escolas de Ensino Fundamental. Durante esse ano, foram atendidos cerca de 50 alunos, com deficiências intelectual e auditiva. Não encontramos registros desses atendimentos e números mais precisos, uma vez que o grupo de 
professoras itinerantes não tinha uma coordenação, não havendo, assim, reuniões conjuntas e nem momentos para troca de experiências ou informações.

Este contexto foi organizado no ano de 2010, quando se estabeleceu uma coordenação para esse grupo e houve a descentralização dos atendimentos da área da Deficiência Intelectual. Para tanto, foi necessária a contratação de 15 professores com habilitação em: Deficiência Mental, Auditiva e Visual. Em todas as 21 escolas de Ensino Fundamental do município havia alunos com deficiência incluídos, alguns da comunidade e outros encaminhados para a inclusão pelo CIEREducação (Centro Integrado de Reabilitação, única escola especializada do município). Desta forma, o serviço itinerante das professoras especialistas foi organizado em Blocos de Atuação. Seguem abaixo as informações da Secretaria de Educação de Hortolândia (2011).

Os blocos funcionam de formas diferentes nas Escolas Municipais de Ensino Fundamental (EMEF) e nas Escolas Municipais de Educação Infantil (EMEI). Como os sujeitos de nossa pesquisa foram os professores de EF, consideraremos apenas a organização do serviço itinerante no Ensino Fundamental, visto que não há aulas de EF na Educação Infantil neste município.

Nas EMEF, o serviço funciona da seguinte forma: cada professora tem um bloco de escolas, composto por três ou quatro unidades, nas quais ela tem os dias delimitados para estar durante o período de trabalho, manhã ou tarde. Cada professora passa, então, dois períodos por semana em cada escola, onde tem estabelecidos os alunos que devem passar pelo Atendimento Educacional Especializado (AEE). Os atendimentos são realizados durante 50 minutos, no horário de aula do aluno, sendo cada um atendido no mínimo uma vez por semana, de acordo com o número de alunos com deficiência da unidade de ensino. No ano de 2010, o município recebeu 13 salas de recurso onde são realizados o $\mathrm{AEE}$, e as escolas que não as têm disponibilizam espaços como biblioteca, sala de informática ou alguma sala "vaga" para o atendimento.

O grupo de professores de Educação Física que atendia as escolas de Ensino Fundamental I do município de Hortolândia, no ano de 2011, era composto por 18 profissionais. No entanto, três deles atuavam na rede há menos de um ano, um não consentiu em participar da pesquisa, e outro atuava apenas na escola especial, por isso foram excluídos do estudo. Analisamos, então, as respostas do grupo formado por 13 professores. Como principal critério de seleção dos sujeitos levou-se em consideração o tempo de trabalho na função, sendo incluídos na pesquisa aqueles que atuavam desde o ano de 2010 nas escolas do município. Esse critério de seleção foi adotado, uma vez que os serviços do AEE se organizaram a partir de 2010 e, consequentemente, aqueles sujeitos que participaram de todo o processo têm maiores experiências para contribuir com a pesquisa. Suas contribuições foram registradas por meio de um questionário aplicado em seus horários de trabalho pedagógico coletivo.

Pensar a Prática, Goiânia, v. 17, n. 1, p. 01-294, jan./mar. 2014 
A análise de conteúdo foi utilizada para verificar como os envolvidos no processo de inclusão educacional avaliam as situações que vêm vivenciando atualmente. Adotamos a incidência de palavras-chave, a abordagem semelhante e a conceituação comum como critérios para a formulação das categorias para análise (PUGLISI; FRANCO, 2005; MACHADO, 1991).

A pesquisa foi submetida e aprovada pelo Comitê de Ética em Pesquisa CEP da Faculdade de Ciências Médicas - FCM da UNICAMP, sob o número de processo 0396.0.146.000-09/2009. Os participantes, após receberem as informações referentes à pesquisa, consentiram em contribuir para o trabalho assinando o Termo de Consentimento Livre e Esclarecido.

\section{Discussão dos Resultados}

Para melhor compreensão e análise dos dados, dividimos esse tópico de acordo com as contribuições referentes a: Identificação da criança com deficiência na escola; Informações sobre o aluno com deficiência; Necessidade de modificações na metodologia das aulas; Engajamento da família; e a Ação municipal.

\section{A identificação e o encaminhamento}

Seis professores $(46,1 \%)$ citaram que a identificação das crianças com deficiência, durante o ano escolar, acontece por meio de encaminhamento ao CIER, onde são realizadas avaliações médicas. Quatro professores $(30,7 \%)$ citaram a participação da professora de sala e da coordenação numa identificação inicial, e posterior encaminhamento para avaliações. Apenas um professor $(7,6 \%)$ citou que também participa da identificação, auxiliando no relatório. Percebemos, portanto, que esses profissionais não se colocam como participantes neste processo de identificação e encaminhamento, mostrando-se alheios a isso.

Destacamos, no entanto, que a Educação Física é uma disciplina vinculada à área da Saúde, na qual a formação abarca alguns conhecimentos de aspectos biológicos e de desenvolvimento humano que possibilitam ao profissional ter um olhar diferenciado sobre questões referentes a comportamentos motores atrasados, assim como o espaço da aula também favorece a percepção dos comportamentos sociais dos alunos. Dessa forma, acreditamos que o professor de Educação Física traria contribuições importantes nesta avaliação precoce e, por isso, deveria ser incluído, ou se incluir, neste processo de identificação e discussão de alunos para encaminhamentos ao CIER.

Acreditamos, ainda, que, possivelmente, a postura destes profissionais diante de seus alunos e da escola também não contribua para a sua participação neste momento do encaminhamento, visto que seus relatos sugerem que eles não se comprometem com este aspecto. Consideramos essa postura resultado de um resquício histórico advindo da década de 1930, tempo em que a doutrina militaris- 
ta e higienista proibia a matrícula em estabelecimento de ensino secundário de aluno cujo estado patológico o impedia permanentemente da prática nas aulas de Educação Física (CARMO, 1991; SILVA, 2005). Mesmo falando de algumas décadas passadas, esse descaso ou desconhecimento das pessoas com deficiência por parte das escolas e o fato de serem tratadas como não aptas para a prática de esportes, fez e faz com que muitos profissionais da área ainda mantenham essa visão segregacionista.

\section{Informações sobre a criança com deficiência}

Quando perguntados sobre as informações necessárias a respeito do aluno com deficiência, a grande maioria do grupo $(76,9 \%)$ respondeu que não recebe nenhuma informação. Os professores citam que faltam capacitações para orientações específicas, que as informações não chegam até eles, e que eles têm que "correr atrás". Apenas um professor $(7,6 \%)$ afirmou que as informações são suficientes, no entanto, ele mesmo busca essas informações com a professora da sala e com a coordenadora. Por fim, um dos professores $(7,6 \%)$ considera que, dependendo do caso, recebe informações, e às vezes não recebe, portanto avaliou como "regular".

Entre o grupo que relatou não receber informações, destacamos alguns pontos interessantes:

"Não. Às vezes não existe nenhuma orientação, somente quando verifico algumas situações e vou perguntar, mas quase nunca os especialistas que trabalham com as crianças orientam o professor de EF" (PROF EF 1).

"Não, muitas vezes as informações não chegam nem a ser passadas para nós, depende da gente ir atrás e procurar saber algo sobre o aluno" (PROF EF 2).

Notamos que a transversalidade das ações do Ensino Especial para o Regular, proposta pelo decreto 6.571/2008 (BRASIL, 2008), não acontece quando focamos nosso olhar na prática do professor de Educação Física. Como esta é disciplina obrigatória da escola, este professor faz parte do rol de profissionais que irão participar do processo de inclusão das crianças com deficiência e, portanto, deve haver uma comunicação e troca de informações entre ele e os professores de Educação Especial, no caso de Hortolândia, as professoras itinerantes. Além disso, a gestão da escola deveria inteirar os professores de EF a respeito das informações sobre a deficiência do aluno e demais observações obtidas em relatórios e conversas com os pais.

Acreditamos, no entanto, que a postura dos professores de Educação Física, conforme relatado no item acima, também auxilie nessa sua "exclusão" do processo, conforme também relata Salerno et. al. (2011) quando destaca que a au- 
sência de profundidade sobre o assunto "deficiência" nos cursos de formação inicial favorece a manutenção dos conceitos e pré-conceitos que limitam a prática e o envolvimento do professor. Além disso, Rodrigues (2003) alerta para a falta de espaços e programas na escola para uma formação continuada, ponto que foi citado pelos professores entrevistados.

\section{A metodologia das aulas}

Interessava-nos saber se a presença dos alunos com deficiência na turma influenciava a metodologia das aulas de EF, ou seja, se isso exigia dos professores modificações na metodologia. Sete professores $(53,8 \%)$ responderam que são necessárias modificações na metodologia, citando que propõem atividades diferenciadas para o aluno com deficiência, e que são necessárias adaptações nas atividades:

"Sim. Tempo de atividades, comunicação, adaptações minhas e das próprias crianças e mudanças em algumas atividades propostas" (PROF EF 3).

Dois professores $(15,3 \%)$ responderam que as modificações dependem da aula proposta e da deficiência do aluno. Quatro deles (30,7\%) relataram que não são necessárias modificações na metodologia, apenas algumas adaptações nas atividades.

É interessante destacar que a grande maioria falou em adaptações das atividades, porém discordou sobre modificações na metodologia. Podemos observar que, para alguns professores, as adaptações são consideradas penosas e, por isso, eles consideram também mudanças na metodologia. Ao passo que outros já não se incomodam com tais adaptações, visto que, com a heterogeneidade observada nas salas, constantemente se torna necessário adaptar algum material ou estratégia.

Não foram realizadas observações das aulas dos entrevistados, no entanto, podemos apontar que a dificuldade com as adaptações das atividades e nas modificações da metodologia devem estar relacionadas à cultura desportiva e competitiva que ainda são muito presentes nas aulas de EF (SEABRA JUNIOR, 2006). A fim de superar essas dificuldades e efetivamente auxiliar no processo de inclusão, Salerno (2009) destaca que o professor precisa entender que uma metodologia mais aberta a possibilidades favorece a criação e recriação de movimentos e permite ao aluno a exploração e o conhecimento do próprio corpo, descobrindo suas potencialidades e também suas limitações. Neste sentido, o importante não é o movimento perfeito e padronizado, mas aquilo que cada um consegue fazer dentro de suas possibilidades.

\section{A família}


Muitos professores demonstraram visões negativas a respeito da participação da família na inclusão de crianças com deficiência. Eles apontam que não há participação da família na escola $(23,07 \%)$, e que muitos pais só participam quando são solicitados $(38,4 \%)$. Foi interessante notar que dois professores citaram não ter conhecimentos sobre o engajamento da família no processo de inclusão. Consideramos tal fato de extrema relevância, uma vez que o professor de EF deve estar a par das discussões e situações que envolvem seus alunos. Apenas um dos participantes da pesquisa demonstrou esse interesse:

"Com a área da EF a familia é totalmente relapsa, pois já pedi várias vezes que alguns pais viessem falar comigo e nunca vieram" (PROF EF 5).

Mais uma vez percebemos um distanciamento do professor de EF, agora com relação à família. Nos relatos pode-se notar que eles não têm muito o que discutir sobre essse ponto, talvez por não considerarem importante o professor de EF ter contato com a família do aluno com deficiência. Ou também, acreditamos que possa haver um sentimento de não pertencimento à escola e, consequentemente, com seus problemas e desafios.

$\mathrm{O}$ volume e organização das aulas dos professores de EF (cinco turmas por período, às vezes em mais de uma escola) favorecem uma prática mecânica e dispersa dos problemas do dia a dia, visto que cada turma tem aulas apenas duas vezes por semana, com duração de 50 minutos cada. Essa rotatividade de alunos unida à falta de tempo e espaço para a troca de informações e ideias sobre o contexto escolar reforça o fato de os professores não assumirem responsabilidade com o processo de inclusão.

Consideramos estes aspectos importantes e, por isso, eles merecem atenção especial dos gestores do município, uma vez que o professor de EF tem papel fundamental na inclusão escolar, conforme afirma Rodrigues (2003), ao levantar os seguintes pontos de contribuição: flexibilidade inerente aos seus conteúdos, o que conduziria a possibilidades para todos os alunos; professores são vistos como profissionais que desenvolvem atitudes mais positivas perante os alunos, já que levantam menos problemas e com maior facilidade encontram soluções para casos difíceis; entende-se que a aula de EF permite um amplo envolvimento de todos, pois sua organização pode suscitar uma participação e um grau de satisfação elevados de alunos com níveis de desempenho muito diferentes.

\section{A ação municipal}

Sobre a organização do poder público para a inclusão dos alunos com deficiência do município, os professores de EF não se mostraram satisfeitos. Cinco professores $(38,4 \%)$ relataram que a descentralização dos atendimentos do CIER aconteceu sem um preparo anterior da escola, tanto estrutural como de recursos 
humanos. Dois $(15,3 \%)$ citaram que falta mais apoio da escola e da Secretaria de Educação. Quatro deles (30,07\%) afirmaram que não há um modelo de trabalho, demonstrando não terem conhecimento da recente organização do municipio para atender essas crianças. Um professor $(7,6 \%)$ citou a falta de acompanhamento familiar para melhorar o processo, e apenas um se mostrou satisfeito com o que vem acontecendo, citando inclusive a contratação de estagiários para auxiliar nas aulas de EF.

O desconhecimento relatado por um grupo específico de professores sobre a organização da inclusão também foi notado na maioria dos demais relatos, visto que eles pouco falaram sobre esse assunto. Consideramos, assim, que os professores de EF não estão a par dos acontecimentos referentes à inclusão escolar das crianças com deficiência no município. Este fato remete às demais questões já apresentadas, e nos permite afirmar que a EF escolar do município de Hortolândia demonstra um distanciamento da escola, principalmente no que concerne às questões relativas à inclusão.

\section{Conclusão}

De acordo com o que foi levantado nas entrevistas com este grupo, pudemos perceber que os professores de EF não participam do processo de identificação e encaminhamento de crianças portadoras de deficiência para a avaliação, mesmo contando com conhecimentos referentes à área da Saúde que auxiliariam nesta etapa. Também constatamos que estes professores não recebem informações sobre o aluno com deficiência, tendo que buscá-las com a gestão escolar.

Sobre mudanças na metodologia das aulas, percebemos que o grupo se dividiu, porém todos apontaram para as adaptações das atividades. Nos últimos dois pontos (o engajamento da família e a ação municipal na inclusão escolar), verificamos o distanciamento dos professores de EF com este processo, visto que pouco comentaram sobre os assuntos e alguns afirmaram não ter conhecimentos ou informações a este respeito.

Acreditamos que a própria organização da escola possa estar favorecendo este distanciamento da área da EF do processo de inclusão escolar. A rotatividade das turmas, o número reduzido de aulas, o número excessivo de alunos por sala, além da postura do professor, que não obteve conhecimentos durante sua formação, e que convive com os problemas da educação brasileira (baixos salários, falta de incentivo, entre outros), podem ser fatores que consolidem ainda mais esse distanciamento.

Somado a isso, consideramos relevante salientar a individualidade de cada professor entrevistado, conforme aponta Seabra Junior (2006). Segundo o autor, cada professor, no interior de sua individualidade, tem convicções e perspectivas construídas sobre diferentes pilares, conforme o momento histórico e político vivenciado. Assim, sua atuação deve ser entendida como uma inter-relação de dife- 
rentes aspectos, além dos conhecimentos acadêmicos, pois o envolvimento com a causa e a busca por diferentes metodologias e possibilidades perpassa pelos conceitos e pré-conceitos vividos e compreendidos por cada sujeito no decorrer de suas vidas.

Concluímos, assim, que os professores de Educação Física de HortolândiaSP não participam efetivamente da inclusão escolar de crianças com deficiência. Isto se deve, principalmente, pelas concepções da deficiência e pela prática pedagógica da EF. Podemos observar que, dentro do pouco comprometimento, suas concepções estão pautadas em uma vertente médico-corretiva que considera a criança com deficiência como um paciente que precisa de cuidados, e, portanto, não tem seu espaço nas práticas da escola.

A isenção de responsabilidade com esses alunos, somada às abordagens tecnicistas que ainda rondam a prática pedagógica da EF, continuam a reforçar a ideologia dominante, que espera que cada nicho de profissionais esteja preocupado apenas com o seu fazer, não havendo interações e discussões. Isso, inclusive, porque estes momentos de reflexão podem ser estopins para reivindicações maiores, as quais viriam a ameaçar a ordem vigente.

Para superar este quadro, destacamos a necessidade do oferecimento de cursos de formação continuada para sensibilização, seguidos de conhecimentos sobre as deficiências, a fim de promover mudanças "de dentro para fora", para que os professores de EF se sintam responsáveis e participantes efetivos da inclusão escolar das crianças com deficiência. Um caminho necessário é o oferecimento de momentos de reflexão entre os professores, não só para trocarem informações sobre os alunos com deficiência, como também para discutirem a respeito das condições atuais da educação brasileira.

O discurso dos profissionais da Educação Física, fundamentado na discordância de como está sendo implantada a inclusão no sistema escolar, não é o suficiente para marcar um posicionamento sem uma fundamentação científica. Discordar é não ter uma proposta, pois acabamos recaindo na retórica de ser contra, sem vislumbrar nenhuma contribuição. $O$ movimento inclusivista perpassa por mudanças nos conceitos, costumes, e práticas estabelecidos há décadas pela sociedade. Nós temos a oportunidade de participar deste momento que visa ampliar o conhecimento em torno das pessoas com deficiência. Portanto, apontamos a necessidade de continuar estudando, refletindo e discutindo propostas, uma vez que as reflexões são formas dos profissionais da Educação/Educação Física avançarem no tema.

\section{PHYSICAL EDUCATION AND SCHOOL INCLUSION: THE PARTICIPATION OF TEACHERS IN HORTOLÂNDIA-SP}




\begin{abstract}
The objective of this study was to present the participation of physical education teachers in the school inclusion for children with disabilities in Hortolandia City, SP. The content analysis performed from the questionnaires, it was possible to notice that the group of 13 teachers do not participate in the process of identification and engagement of children for evaluation and do not receive information about the disable student and identified the need for adjustments in class activities. The conclusion was that the City of Hortolandia needs to promote an approach of EF teachers with school inclusion, through awareness courses and continuing education.
\end{abstract}

Keywords: Disabled Children. Physical Education. Municipal Organization.

\title{
INCLUSIÓN ESCOLAR Y EDUCACIÓN FÍSICA: LA PARTICIPACIÓN DE LOS PROFESORES DE LA CIUDAD DE HORTOLÂNDIA - SP
}

\section{Resumen}

Lo objetivo del artículo fue enseñar cual es la participación de los profesores de Educación Física para la inclusión escolar de chicos con discapacidad de la ciudad de Hortolândia - SP. Fue utilizada la análisis de contenido para el estudio de cuestionarios rellenados por profesores. Percibimos que 13 maestros no participan del proceso que objetiva identificar y encaminar niños para evaluación, no reciben informaciones sobre los estudiantes con discapacidad y realizan adaptaciones en las actividades de clase. Concluimos que la ciudad de Hortolândia necesita promover la aproximación de los profesores de EF con el proceso inclusivo escolar, por intermedio de cursos para sensibilización y formación continuada.

Palabras clave: Niños com Discapacidad. Educación y Entrenamiento Físico. Organización Municipal.

\section{Referências}

ARAÚJO, P. F. de. O desporto adaptado no Brasil: onde tudo começou. In: VERARDI, Paulo Henrique et al. Desafiando as diferenças. São Paulo: Sesc, 2003. p. 82-93.

BRACHT, Valter. Sociologia crítica do esporte: uma introdução. 3. ed. Ijuí: Unijuí, 2005.

BRASIL. Ministério da Educação. Plano Nacional de Educação - PNE. Brasília: INEP, 2001.

BRASIL. Decreto $\mathbf{n}^{0}$ 6.571, 17 de setembro de 2008. 2008. Disponível em: < http://www.planalto.gov.br/ccivil_03/_Ato2007-2010/2008/Decreto/D6571.htm>. Acesso em: 20 mai. 2010. 
BROTTO, F. O. Jogos Cooperativos: O jogo e o esporte como um exercício de convivência. Dissertação (Mestrado em Educação Física) - Faculdade de Educação Física, Universidade Estadual de Campinas, Campinas, 1999.

CARMO, A. A. do. Deficiência física: a sociedade brasileira cria, recupera e discrimina. Brasília: MEC/Secretaria dos Desportos/PR, 1991.

DEMO, P. Metodologia do conhecimento científico. 1. ed. São Paulo: Atlas, 2009.

FILUS, J. F.; LIMA, S. M. T.; RODRIGUES, V. Inter-relações discentes de uma turma inclusiva em aulas de Educação Física, Revista Teoria e Prática da Educação, v. 8, n. 1, p.55-61, 2005.

FLORENCE, R. B. P. A Educação Física na rede pública do município de São João da Boa Vista - SP e o portador de necessidades especiais: do direito ao alcance. 2002. 95f. Dissertação (Mestrado em Educação Física) - Faculdade de Educação Física, Universidade Estadual de Campinas, Campinas, 2002.

MACHADO, M. N. M. Entrevista de pesquisa: a interação entrevistador / entrevistado. Tese. (Doutorado) - Belo Horizonte, 1991.

PUGLISI, M.L.; FRANCO, B. Análise de conteúdo. 2. ed. Brasília: Líber Livro, 2005.

RODRIGUES, D. A Educação Física perante a Educação Inclusiva: reflexões conceptuais e metodológicas, Revista da Educação Física/UEM, Maringá, v. 14, n. 1, p. 67-73, 2003.

SALERNO, M. B.; FILUS, J. F.; SILVA, R. F.; ARAÚJO, P.F. A inclusão sob a ótica dos alunos de graduação em Educação Física, Revista Pensar a Prática, Goiânia, v. 15. n. 2, p. 380-392, 2012.

SALERNO, M. B. Interação entre alunos com e sem deficiência nas aulas de Educação Fìsica Escolar: validação de instrumento. 2009. 112f. Dissertação (Mestrado em Educação Física) - Faculdade de Educação Física, Universidade Estadual de Campinas, Campinas, 2009.

SANCHES JUNIOR, M. L. Uma leitura da questão da deficiência e da inclusão no ensino municipal de Hortolândia: olhares e ações da docência de Educação Física e de seus pares. 2009. 102f. Dissertação (Mestrado em Educação Físi- 
ca) - Faculdade de Educação Física, Universidade Estadual de Campinas, Campinas, 2009.

SEABRA JUNIOR, L. Inclusão, necessidades especiais e Educação Física: considerações sobre a ação pedagógica no ambiente escolar. 2006. 119f. Dissertação (Mestrado em Educação Física) - Faculdade de Educação Física, Universidade Estadual de Campinas, Campinas, 2006.

SECRETARIA DE EDUCAÇÃO - HORTOLÂNDIA. Apresentação de Workshop. Material impresso cedido pela Coordenação de Inclusão. 2011.

SILVA, R. F. da; SEABRA JÚNIOR, L.; ARAÚJO, P. F. de. Educação física adaptada no Brasil: da história à inclusão educacional. São Paulo: Phorte, 2008.

SILVA, R. F. da. A ação do professor de ensino superior na educação física adaptada: construção mediada pelos aspectos dos contextos históricos, políticos e sociais. 2005. 159f. Dissertação (Mestrado em Educação Física) - Faculdade de Educação Física, Universidade Estadual de Campinas, Campinas, 2005.

SOLER, R. Educação Física Inclusiva na escola: em busca de uma escola plural. Rio de Janeiro: Sprint, 2005.

VAGO, Tarcísio M. O "esporte na escola" e o "esporte da escola": da negação radical para uma relação de tensão permanente - um diálogo com Valter Bracht. Movimento, Porto Alegre, Ano III, n. 5, 1996.

Endereço para correspondência:

fujifilus@yahoo.com.br

Josiane Filus Freitas

Instituto Adventista de São Paulo,

Faculdade Adventista de Hortolândia

R. Pr. Hugo Gegembauer, 265

Pq. Ortolandia

13184990 - Hortolândia, SP - Brasil 